\title{
DÉFICIT DE POLINIZAÇÃO DA ACEROLEIRA NO PERÍODO SECO NO SEMIÁRIDO PARAIBANO ${ }^{1}$
}

\author{
ROZILEUDO DA SILVA GUEDES², FERNANDO CÉSAR VIEIRA ZANELLA ${ }^{3}$, \\ CELSO FEITOSA MARTINS ${ }^{4}$ E CLEMENS SCHLINDWEIN ${ }^{5}$
}

RESUMO - A aceroleira é uma importante frutífera tropical que pode produzir frutos o ano todo na região semiárida do Nordeste do Brasil, caso seja utilizada a irrigação. Como a aceroleira depende da polinização por abelhas coletoras de óleos florais para apresentar uma produção satisfatória de frutos, este trabalho teve como objetivo avaliar a abundância de polinizadores e o sucesso reprodutivo da cultura no período seco, no semiárido paraibano. Foram registradas quatro espécies de abelhas nativas da tribo Centridini, todas consideradas polinizadoras efetivas da aceroleira, pela frequência nas flores e comportamento: Centris aenea Lepeletier, C. tarsata Smith, C. fuscata Lepeletier e C. trigonoides Lepeletier (Apidae, Centridini). A frequência de visitas às flores foi menor no período seco do que no período chuvoso. A polinização cruzada manual complementar resultou em incremento de 61 a 74\% na produção de frutos durante o período seco, nos dois anos avaliados, indicando que há um grande déficit de polinização devido à baixa abundância de abelhas Centris. Esse resultado implica a necessidade de manejo dos polinizadores, especialmente em cultivos irrigados durante o período seco, na região semiárida do Nordeste do Brasil.

Termos para indexação: Malpighia emarginata, semiárido brasileiro, Centridini, sucesso reprodutivo, polinização cruzada manual complementar.

\section{POLLINATION DEFICIT OF ACEROLA ORCHARDS DURING THE DRY SEASON IN THE SEMIARID REGION OF NORTHEASTERN BRAZIL}

\begin{abstract}
The Acerola or the Caribbean cherry is an important tropical fructiferous tree, which produces all over the year in the semiarid region of Northeastern Brazil if orchards are irrigated. As this culture depends on the pollination by oil-collecting bees to get a good production, the availability of pollinators, the reproductive success and the possibility of pollination deficit of Malpighia emarginata were studied during the dry season in a site of the state of Paraiba. Four species of native Centridini bees were observed and considered efficient pollinators due to their frequency and behavior on flowers: Centris aenea Lepeletier, $C$. tarsata Smith, C. fuscata Lepeletier and C. trigonoides Lepeletier (Apidae, Centridini). The frequency of visits on flowers within the dry period was lower than in the wet one. Additional experimental hand crosspollination incremented fruit production by 61 to $74 \%$ during dry season. This shows a strong pollination deficit due to the low abundance of Centris bees in this period. This result implies on the necessity to manage the availability and abundance of pollinators to get a higher production, especially in irrigated orchards of acerola during the dry season.
\end{abstract}

Index terms: Malpighia emarginata, Brazilian semiarid region, Centridini, reproductive success, complementary hand cross-pollination.

\footnotetext{
${ }^{1}$ (Trabalho 101-10). Recebido em: 19-04-2010. Aceito para publicação em: 29-09-2010. Trabalho realizado no âmbito do Projeto PROBIO polinizadores BIRD/GEF/MMA/CNPq.

${ }^{2}$ Engenheiro Florestal, Pós-Graduação em Ciências Florestais, Universidade Federal de Campina Grande (UFCG), Campus de Patos, Rodovia Patos-Teixeira, Caixa Postal 64, CEP 58700-960, Patos-PB. E-mail: rozileudo@gmail.com

${ }^{3}$ Biólogo, Dr., Laboratório de Ecologia e Biogeografia de Insetos da Caatinga, Unidade Acadêmica de Ciências Biológicas, UFCG, Patos-PB. E-mail: fcvzanella@gmail.com

${ }^{4}$ Biólogo, Dr., Departamento de Sistemática e Ecologia, CCEN, UFPB, João Pessoa-PB. E-mail: cmartins@dse.ufpb.br

${ }^{5}$ Biólogo, Dr., Laboratório Plebeia - Ecologia de Abelhas e da Polinização, Departamento de Botânica, UFPE, Recife-PE. E-mail: schlindw@gmail.com
} 


\section{INTRODUÇ̃̃O}

A aceroleira (Malpighia emarginata DC, Malpighiaceae), importante frutífera tropical, é uma planta rústica, que cresce como arbusto ou arvoreta e produz frutos conhecidos pelo elevado conteúdo de ácido ascórbico (vitamina C), que segundo Mezadri et al. (2006) apresentam de $695 \mathrm{a} 4.827 \mathrm{mg}$ por $100 \mathrm{~g}$ de polpa. O Brasil possui condições edafoclimáticas que torna viável economicamente a aceroleira em quase toda sua extensão, sendo a região Nordeste onde melhor se adapta (PAIVA et al., 1999). É um dos maiores produtores mundiais desta fruta, com grande parte de sua produção comercializada na forma de polpa (MATSUURA et al., 2001).

A aceroleira pode florescer e frutificar várias vezes durante o ano, conforme as condições meteorológicas locais, podendo chegar até nove safras/ ano em regiões tropicais (MUSSER, 1995). No caso da região semiárida tropical do Nordeste do Brasil, a produção no período seco depende da utilização de irrigação. No entanto, a floração não garante a formação de frutos, pois essa planta depende de polinizadores para uma boa frutificação. As abelhas solitárias da tribo Centridini, especializadas na coleta de óleos florais, são as responsáveis pela polinização dessa frutífera (RAW, 1987; FREITAS et al., 1999; SCHLINDWEIN et al., 2006). Mesmo quando há abundância de outras abelhas, como as africanizadas Apis mellifera L., estas não contribuem significativamente para a polinização (FREITAS et al., 1999; MARTINS et al., 1999; VILHENA;AUGUSTO, 2007).

A dependência de agentes polinizadores bióticos não é exclusiva da aceroleira. Considerase que, sem agentes polinizadores, a maioria das plantas não se reproduziria sexuadamente. Cerca de $75 \%$ das culturas e $80 \%$ das espécies de plantas com flores dependem da polinização por animais, como morcegos, pássaros, borboletas, mariposas, vespas, besouros, moscas e, principalmente, abelhas (KEVAN; IMPERATRIZ-FONSECA, 2002; RICKETTS et al., 2008). Para as espécies agrícolas cultivadas, estima-se que aproximadamente $73 \%$ são polinizadas por abelhas (FAO, 2004).

Como a região semiárida do Nordeste do Brasil apresenta uma forte sazonalidade, com estação seca prolongada, que usualmente dura de seis a nove meses, há uma redução na abundância de recursos florais e consequente diminuição significativa na abundância e diversidade de abelhas solitárias (ZANELLA; MARTINS, 2003; ZANELLA, 2008). Desse modo, a escassez de abelhas da tribo Centridini pode ser um fator limitante para a produção de acerolas nesse período. Essa possível limitação da produtividade é importante para a viabilidade da cultura, uma vez que, para se obter o seu florescimento, é necessária a irrigação dos plantios, o que, além de consumir água, um recurso escasso, implica gasto com energia e mão de obra.

Este estudo teve por objetivo avaliar a abundância de abelhas polinizadoras da aceroleira no período seco, em um pomar na região do semiárido paraibano, e o sucesso reprodutivo da cultura, para verificar se ocorre déficit de polinização.

\section{MATERIAL E MÉTODOS}

O estudo foi conduzido no "Sítio Fechado", distrito de Santa Gertrudes $\left(7^{\circ} 01^{\prime} \mathrm{S}\right.$ e $37^{\circ} 17^{\prime} \mathrm{W}$; altitude de $250 \mathrm{~m}$ ), no município de Patos, Paraíba, Brasil, de abril de 2004 a agosto de 2005. Situado no Sertão paraibano, apresenta temperatura média anual de $27{ }^{\circ} \mathrm{C}$ e pouca variação entre as médias mensais. A pluviosidade anual média é de $750 \mathrm{~mm}$, sendo irregularmente distribuída entre os meses. Existem duas estações bem distintas durante o ano: uma estação chuvosa (verão-outono), de 3 a 5 meses, com chuvas torrenciais e irregulares, e uma estação seca, de 7 a 9 meses, quase sem chuvas (PARAÍBA, 1985; DUQUE, 2004; MAIA, 2004).

O Sítio Fechado possui 20 ha, sendo 5 ha com plantas frutíferas: mangueiras, coqueiros, goiabeiras, cajueiros, pinheiras e aceroleiras. O pomar comercial de aceroleiras conta com aproximadamente 200 indivíduos, sem variedade definida, com espaçamento $3 \times 3 \mathrm{~m}$. Nos arredores do pomar, há áreas de pasto nativo e vegetação típica de caatinga secundária e um pequeno açude que seca no período seco. O pomar está sobre um solo de aluvião, ao lado de um córrego temporário, e acerca de meio quilômetro da barragem de um grande açude, que apresenta água armazenada o ano todo.

A produção ocorre tanto no período chuvoso como no seco. Nesse período, o pomar é mantido em estresse hídrico por aproximadamente dois meses e, após uma capina entre as fileiras, é irrigado, com uso de aspersão nos primeiros dias e, posteriormente, com irrigação por gotejamento até a maturação dos frutos. Havendo disponibilidade de água, são obtidas até duas safras na seca.

A antese foi acompanhada em campo, em 50 botões florais marcados individualmente, distribuídos em três indivíduos, avaliando-se a longevidade floral, a ocorrência de sincronização entre flores e o horário da deiscência das anteras.

Para avaliar a abundância de polinizadores da aceroleira, foi registrado o número de visitas às flores 
por hora, mediante observações diretas de 30 minutos por hora, das 5 às 17 horas. As observações foram realizadas em três épocas distintas: abril (período chuvoso) e setembro (período seco), ambos em 2004 e final de agosto de 2005 (início do período seco). Em cada amostragem, marcaram-se 20 flores em duas plantas próximas que se encontravam mais floridas. Para o reconhecimento das espécies de abelhas no campo, foi realizada uma coleta qualitativa dos visitantes florais com auxílio de rede entomológica. As abelhas coletadas foram sacrificadas em frascos mortíferos contendo cianeto de potássio, montadas, identificadas e depositadas na coleção do Laboratório de Ecologia e Biogeografia de Insetos da Caatinga (LEBIC), da Universidade Federal de Campina Grande, Patos, Paraíba.

O sistema reprodutivo foi verificado em campo, em abril e agosto de 2005, por meio de experimentos clássicos de polinização controlada (KEARNS; INOUYE, 1993). Para isso, botões florais em pré-antese foram selecionados, e frutos, flores e outros botões vizinhos, eliminados, e o ramo ensacado com tecido tipo organza. Para comparação, foram marcadas e acompanhadas flores não isoladas, sujeitas à livre visitação.

Para a realização de polinização cruzada manual, anteras abertas de flores de, pelo menos, três outros indivíduos foram encostadas diretamente aos estigmas de flores previamente ensacadas. Para a autopolinização manual, o procedimento foi idêntico, todavia o pólen utilizado na polinização foi retirado das anteras da própria flor. Após os tratamentos, as flores foram novamente ensacadas e permaneceram assim até o murchamento. Cada tratamento foi realizado em 30 flores, selecionadas aleatoriamente em cinco indivíduos. A polinização manual foi realizada entre 8 e 12 horas, e registrou-se a formação de frutos nos tratamentos sete dias após a polinização. Para a identificação das flores nas quais foram realizados os testes, foram utilizadas fitas, com cores específicas para cada tipo de polinização, fixadas no pedicelo da flor.

Para avaliar a produção de frutos e a ocorrência de um possível déficit de polinização, foram conduzidos experimentos em delineamento de blocos casualizados, em dois momentos de período seco: em 2004, entre setembro e novembro, e em agosto de 2005, início do período seco. A taxa de frutificação sob polinização natural foi comparada à obtida no experimento do sistema reprodutivo, realizado no período chuvoso (abril) e início do período seco de 2005 (início de agosto). Deve ser ressaltado que a abundância de abelhas solitárias continua relativamente alta por um tempo após o final do período chuvoso (ZANELLA; MARTINS, 2003).

Cada unidade amostral foi constituída por quarenta flores marcadas em um indivíduo, sendo vinte localizadas na parte externa da copa e vinte na parte interna. Dez flores de cada conjunto (totalizando vinte) foram polinizadas manualmente de forma complementar, com pólen de outros indivíduos. Como as flores ficaram expostas aos visitantes florais, espera-se que a taxa de frutificação tenha sido a máxima possível para as condições locais. As outras vinte flores foram acompanhadas para se verificar o percentual de frutificação com polinização natural, sem polinização cruzada manual complementar. Na primeira amostragem, foram utilizadas 15 plantas, perfazendo um total de 600 flores. Na segunda amostragem (início do período seco), utilizaram-se oito plantas, sendo sete com repetição para perfazer um total de 600 flores. Este procedimento foi necessário devido ao menor número de indivíduos com florada massiva. Os dados coletados foram analisados, empregando-se análise de variância, seguida de teste de Tukey para a comparação de médias.

\section{RESULTADOS E DISCUSSÃO}

As flores de Malpighia emarginata abriram ao amanhecer e duraram apenas um dia. O início da antese foi sincrônico, ocorrendo por volta das 5 $\mathrm{h}$ da manhã, de modo semelhante ao observado por Freitas et al. (1999) no Ceará. No entanto, Gomes et al. (2001), em estudos em Jaboticabal-SP, constataram que algumas flores abriam no período da tarde, entre as 14 e 16 horas, o que não foi observado no presente estudo.

Neste estudo, não foi registrada nenhuma flor que não tenha apresentado deiscência das anteras, diferentemente de Freitas et al. (1999), que não observaram abertura das anteras em $12,5 \%$ das flores. Segundo esses autores, o estigma já está receptivo às 6 horas, o que coincide com o horário de deiscência das anteras e de atividade das abelhas neste estudo.

A intensidade de florada não foi homogênea entre os indivíduos, o que pode ser resultado de diferenças na irrigação e de diferenças intrínsecas dos indivíduos, pois foi observado que algumas características, como: tamanho das folhas e coloração das flores, também foram variáveis. As flores apresentaram usualmente três pistilos, sendo observadas algumas com quatro e cinco, mas aparentemente não há relação entre o número de sementes, de três a cinco, e o tamanho do fruto.

Foram observadas quatro espécies de abelhas solitárias nativas visitando as 20 flores 
marcadas, todas pertencentes à família Apidae, tribo Centridini: Centris (Centris) aenea Lepeletier, 1841, Centris (Trachina) fuscata Lepeletier,1841, Centris (Hemisiella) tarsata Smith, 1874, e Centris (Hemisiella) trigonoides Lepeletier, 1841. Todas apresentaram modo de visitação semelhante, sempre contatando anteras e estigmas florais, enquanto coletavam óleos florais. No período chuvoso (abril de 2004), foi registrado o maior número de visitas (86), e, no período seco, menor, 28 em setembro de 2004 e 36 no início do período seco de 2005, resultando em uma frequência de 4,3; 1,4 e 1,8 visitas por flor/dia, em cada amostragem, respectivamente.

Os resultados de autopolinização e polinização cruzada manual indicam que o pegamento do fruto de M. emarginata, a partir da autopolinização manual, é inferior àquele advindo da polinização cruzada manual (Tabela 1), o que corrobora os resultados encontrados por Freitas et al. (1999) e Lopes et al. (2000). A partir da autopolinização espontânea, a frutificação foi de apenas 6,7\%, enquanto Martins et al. (1999) encontraram 15\% e Freitas et al. (1999) e Schlindwein et al. (2006), na zona da mata de Pernambuco, não obtiveram frutificação em flores não visitadas por insetos.

O valor máximo de frutificação obtido por Freitas et al. (1999), no Ceará, foi de 23,8\% por meio de polinização cruzada manual, muito abaixo do encontrado no presente trabalho. Martins et al. (1999), em condições de clima de altitude em Areia, Paraíba, obtiveram apenas 18\%, enquanto Schlindwein et al. (2006), no litoral de Pernambuco, observaram um percentual semelhante ao deste trabalho (45\%). Vários fatores podem determinar a variação na produção de frutos sob polinização cruzada manual, mas os resultados obtidos demonstram a importância da polinização cruzada para uma produção satisfatória de frutos.

Os experimentos de polinização cruzada manual complementar à efetuada por visitantes florais, realizados no período seco, resultaram em um número de frutos significativamente maior do que quando as flores dependeram apenas da atividade de transferência de pólen efetuada pelas abelhas (Tabelas 2 e 3). Isso demonstra que existiu um déficit de polinização na estação seca, o que deve ter resultado da baixa abundância de polinizadores nessa época.

Para garantir uma produção comercialmente viável, desta maneira, são necessárias práticas de manejo dos polinizadores, especialmente de espécies que nidificam em cavidades preexistentes, como Centris tarsata. Essas espécies podem ser manejadas em ninhos-armadilha, como indicado para Centris analis (OLIVEIRA; SCHLINDWEIN, 2009). Para várias culturas de regiões temperadas, a utilização de abelhas solitárias nidificantes em ninhos-armadilha é praticada para garantir ou aumentar a produtividade dos plantios (BOSCH; KEMP, 2005; CANE, 2005; $\mathrm{BOSCH}$ et al. 2006). Contudo, nenhuma das espécies de abelhas solitárias brasileiras está sendo manejada até o momento (OLIVEIRA; SCHLINDWEIN, 2009).

A taxa de frutificação nas duas posições da copa analisadas mostrou que não houve um vingamento significativo maior dos frutos na parte interna da copa, nos períodos avaliados, apesar de os valores serem maiores, exceto em 2005 (Tabela 4). É possível que esse resultado tenha sido determinado por maior probabilidade de queda dos frutos em desenvolvimento na parte externa da copa, podendo ser inclusive apenas devido à passagem de pessoas no local.

A taxa de frutificação, nos dois períodos avaliados, variou muito também entre os indivíduos de aceroleira. Sob polinização natural, variou entre 0 e $50 \%$ por indivíduo, no período seco de 2004 , e entre 10 e $70 \%$, no período seco de 2005 . No tratamento de polinização cruzada complementar, variou entre 5 e $70 \%$ e entre 15 e $80 \%$, em 2004 e 2005 , respectivamente. Essa variação pode estar relacionada à variabilidade genética da aceroleira (PAIVA et al., 1999; LIMA et al., 2003; CARPENTIERI-PÍPOLO et al., 2002) e às diferentes condições por indivíduo, uma vez que o sistema não permitia irrigação e adubação homogêneas entre as plantas.

As maiores taxas de frutificação na estação seca de 2005 resultaram, possivelmente, da melhor condição de irrigação, mas, independentemente disso, na polinização manual complementar, o número de frutos formados foi significativamente maior do que o número de frutos obtidos através da polinização natural, resultando em incremento de 61 a 74\%. Assim como o observado na aceroleira, vários estudos têm demonstrado o aumento na produção de frutos a partir da visitação de insetos polinizadores em diversas outras culturas (MOTA; NOGUEIRA-COUTO, 2002; KLEIN et al., 2003; ROUBIK, 2002; GREENLEAF; KREMEN, 2006).

A taxa de frutificação através de polinização livre, obtida no período chuvoso, quando havia maior abundância de abelhas Centridini nas flores, foi semelhante à do experimento de polinização cruzada manual (Tabela 1). Isso permite interpretar que a abundância de abelhas Centris nesse período foi suficiente para garantir bom pegamento de frutos. Mas, na estação seca, pode-se esperar um incremento 
na taxa de produção de frutos até o nível do obtido por meio de polinização cruzada complementar caso a abundância de polinizadores seja maior e não exista déficit de polinização. Desse modo, deve ser estudada a viabilidade da adoção de medidas de manejo de polinizadores para aumentar sua abundância, especialmente durante o período seco, quando há escassez de frutos no mercado e seu valor de comercialização é maior.

O presente estudo demonstra que, além de fatores usualmente valorizados, como o melhoramento genético e o manejo da cultura, a disponibilidade e a abundância de polinizadores devem ser consideradas como fator importante nos sistemas de produção dessa cultura (OLIVEIRA; SCHLINDWEIN, 2009), para o incremento da produção na região semiárida do Nordeste do Brasil, especialmente no período seco.
Possíveis práticas de manejo indicadas para a conservação e o aumento da densidade de polinizadores são: o não uso de inseticidas, especialmente durante o período de atividade dos polinizadores; a conservação de áreas com vegetação nativa remanescente no entorno dos pomares para oferta de pólen e néctar necessários à manutenção das larvas e adultos das abelhas; enriquecimento da área com plantas fornecedoras de recursos florais, especialmente néctar e pólen; e conservar ou oferecer locais de nidificação das espécies de Centris, como locais de terra exposta ou barrancos onde se encontram ninhos, madeira morta com orifícios ou ninhos-armadilha. Mas a efetividade de ações como: o manejo dos pomares e do entorno e a criação e/ou translocação de ninhos de abelhas solitárias precisa ser estudada e avaliada em cada contexto.

TABELA 1 - Avaliação do sistema reprodutivo da aceroleira em Patos, Paraíba, em 2005.

\begin{tabular}{cccc}
\hline Tratamento & $\mathrm{N}^{\circ}$ Flores & $\mathrm{N}^{\circ}$ Frutos & Frutificação (\%) \\
\hline Autopolinização Espontânea & 30 & 2 & 6,7 \\
Autopolinização Manual & 30 & 5 & 16,7 \\
Polinização Cruzada Manual & 30 & 15 & 50,0 \\
Polinização Natural & 30 & 16 & 53,3 \\
\hline
\end{tabular}

TABELA 2 - Frutificação da aceroleira em flores sujeitas à ação dos polinizadores, com e sem polinização cruzada manual adicional. Período seco, setembro e novembro de 2004.

\begin{tabular}{cccc}
\hline Tratamentos & $\mathrm{N}^{\mathbf{0}}$ de flores & $\mathrm{N}^{\mathbf{0}}$ de Frutos & Frutificação (\%) \\
\hline Polinização manual + natural & 300 & $97 \mathrm{a}$ & 32,3 \\
Polinização natural & 300 & $60 \mathrm{~b}$ & 20,0 \\
\hline
\end{tabular}

*Valores seguidos de letras iguais não diferem entre si, pelo teste de Tukey, a $1 \%$ de probabilidade.

TABELA 3 - Frutificação da aceroleira em flores sujeitas à ação dos polinizadores, com e sem polinização cruzada manual adicional. Período seco, agosto de 2005.

\begin{tabular}{cccc}
\hline Tratamento & $\mathrm{N}^{0}$ de Flores & $\mathrm{N}^{0}$ de Frutos & Frutificação (\%) \\
\hline Polinização manual + natural & 300 & $166 \mathrm{a}$ & 55,3 \\
Polinização natural & 300 & $95 \mathrm{~b}$ & 31,7 \\
\hline
\end{tabular}

*Valores seguidos de letras iguais não diferem entre si, pelo teste de Tukey, a $1 \%$ de probabilidade.

TABELA 4 - Número e porcentagem de frutos da aceroleira (Malpighia emarginata), para os tratamentos "polinização natural" e "polinização natural mais cruzada manual complementar", nas diferentes posições na copa, em 2004 e 2005, na região de Patos-PB.

\begin{tabular}{ccccc}
\hline \multicolumn{5}{c}{$\mathbf{2 0 0 4}$} \\
\hline Tratamento & Posição na Copa & $\mathrm{N}^{\mathrm{o}}$ de Flores & $\mathrm{N}^{\mathbf{0}}$ de Frutos & Frutificação (\%) \\
\hline \multirow{2}{*}{ Polinização Natural } & Externa & 150 & $28 \mathrm{a}$ & 18,7 \\
& Interna & 150 & $32 \mathrm{a}$ & 21,3 \\
\multirow{2}{*}{ Pol. Cruzada Manual + Pol. Natural } & Externa & 150 & $44 \mathrm{a}$ & 29,3 \\
& Interna & 150 & $53 \mathrm{a}$ & 35,3 \\
\hline \multirow{4}{*}{ Tratamento } & Posição na Copa & $\mathrm{N}^{\mathrm{o}}$ de Flores & $\mathrm{N}^{\circ}$ de Frutos & Frutificação (\%) \\
\hline \multirow{2}{*}{ Polinização Natural } & Externa & 150 & $40 \mathrm{a}$ & 26,7 \\
& Interna & 150 & $55 \mathrm{a}$ & 36,7 \\
\multirow{2}{*}{ Pol. Cruzada Manual + Pol. Natural } & Externa & 150 & $73 \mathrm{a}$ & 48,7 \\
& Interna & 150 & $93 \mathrm{~b}$ & 62,0 \\
\hline
\end{tabular}

*Valores seguidos de letras iguais não diferem entre si, pelo teste de Tukey, a 1\% de probabilidade. 


\section{CONCLUSÕES}

1- As quatro espécies de abelhas da tribo Centridini observadas são consideradas polinizadoras efetivas por apresentarem comportamento de visitação adequado.

2- As abelhas polinizadoras apresentam menor abundância durante o período seco na área de estudo.

3- Há um baixo sucesso reprodutivo da aceroleira durante o período seco na área de estudo, em consequência da existência de déficit de polinizadores, sendo constatado o aumento da frutificação por meio de polinização manual complementar.

\section{AGRADECIMENTOS}

Ao Sr. Manoel Pereira da Silva, pela permissão para desenvolver este estudo em sua propriedade; ao PROBIO polinizadores BIRD/GEF/ MMA/CNPq, pelo financiamento do estudo e pela bolsa DTI, concedida ao primeiro autor; à FAPESQ/ $\mathrm{PB}$ e CNPq, pelo apoio à estruturação do Laboratório de Ecologia e Biogeografia de Insetos da Caatinga (LEBIC/UFCG-Patos), e ao CNPq pela bolsa de produtividade em pesquisa à F. C. V. Zanella, C. F. Martins e C. Schlindwein.

\section{REFERÊNCIAS}

BOSCH, J.; KEMP, W. P. Alfalfa leafcutting bee population dynamics, flower availability, and pollination rates in two Oregon alfalfa fields. Journal of Economic Entomology, Lanham, v.98, p.10771086, 2005.

BOSCH, J.; KEMP, W. P.; TROSTLE, G. E. Bee population returns and cherry yields in an orchard pollinated with Osmia lignaria (Hymenoptera: Megachilidae). Journal of Economic Entomology, Lanham, v.99, p.408-413, 2006.

CANE, J. H. Pollination potential of the bee Osmia aglaia for cultivated raspberries and blackberries (Rubus: Rosaceae). HortScience, Alexandria, v.40, p.1705-1708, 2005.

CARPENTIERI-PÍPOLO, V. et al. Novas cultivares de acerola (Malpighia emarginata DC): UEL 3 Dominga, UEL 4 - Lígia e UEL 5 - Natália. Revista Brasileira de Fruticultura, Jaboticabal, v.24, n.1, p.124-126, 2002.
DUQUE, J. G. Perspectivas nordestinas. 2. ed. Fortaleza: Banco do Nordeste do Brasil, 2004. 424p.

FAO. Conservation and management of pollinators for sustainable agriculture - the international response. In: FREITAS, B. M.; PEREIRA, J. O. P. (Ed.). Solitary bees: conservation, rearing and management for pollination. Fortaleza: Imprensa Universitária. 2004. p.19-25.

FREITAS, B. M. et al. Pollination requirements of West Indian cherry (Malpighia emarginata) and its putative pollinators, Centris bees, in NE Brazil. Journal of Agricultural Science, Cambridge, v.133, p.303-311, 1999.

GOMES, J. E. et al. Morfologia floral e biologia reprodutiva de genótipos de aceroleira. Scientia Agricola, Piracicaba, v.58, n.3, p.519-523, 2001.

GREENLEAF, S. S.; KREMEN, C. Wild bee species increase tomato production and respond differently to surrounding land use in Northern California. Biological Conservation, London, v.1, n.33, p.81-87, 2006.

KEARNS, C. A.; INOUYE, D. W. Techniques for pollination biologists. Niwor, Colorado: University Press of Colorado, 1993. 583p.

KEVAN, P. G.; IMPERATRIZ-FONSECA, V. L. (Ed.). Pollinating bees: the conservation link between agriculture and nature. Brasília: Ministry of Environment, 2002. 313p.

KLEIN, A.-M.; STEFFAN-DEWENTER, I.; TSCHARNTKE, T. Bee Pollination and Fruit set of Coffea Arabica and C. canephora (Rubiaceae). American Journal of Botany, Saint Louis, v.90, n.1, p.153-157, 2003.

LIMA, V. L. A. G. et al. Avaliação de teor de antocianinas em polpa de acerola congelada proveniente de frutos de 12 diferentes aceroleiras (Malpighia emarginata D.C.). Ciência e Tecnologia de Alimentos, Campinas, v.23, n.1, p.101-103, 2003.

LOPES, R.; BRUCKNER, C. H.; LOPES, M. T. G. Polinização e vingamento de frutos em aceroleira (Malpighia punicifolia L.). Revista Brasileira de Fruticultura, Jaboticabal, v.22, n.3, p.314-317, 2000. 
MAIA, G. N. Caatinga: árvores arbustos e suas utilidades. São Paulo: D \& Z Computação Gráfica e Editora, 2004. 413 p.

MARTINS, C. G. M.; LORENZON, M. C. A.; BAPTISTA, J. L. Eficiência de tipos de polinização em acerola. Caatinga, Mossoró, v.12, p.55-59, 1999.

MATSUURA, F. C. A. U. et al. Avaliações físicoquímicas em frutos de diferentes genótipos de acerola (Malpighia punicifolia L.). Revista Brasileira de Fruticultura, Jaboticabal, v.23, n.3, p.602-606, 2001.

MEZADRI, T. et al. El fruto de la acerola: composición, características productivas e importancia económica. Archivos Latinoamericanos de Nutrición, Caracas, v.56, p.101-109, 2006.

MOTA, M. O. S. da; NOGUEIRA-COUTO, R. H. Polinização entomófila em pessegueiro (Prunus persica L.). Brazilian Journal of Veterinary Research and Animal Science, São Paulo, v.39, n.3, p.124-128, 2002.

MUSSER, R. dos S. Tratos culturais na cultura da acerola. In: SÃO JOSÉ, A.R.; ALVES, R.E. (Eds.). Acerola no Brasil: produção e mercado. Vitória da Conquista: UESB, 1995. p.47-52.

OLIVEIRA, R.; SCHLINDWEIN, C. Searching for a manageable pollinator for acerola orchards: the solitary oil-collecting bee, Centris analis (Hymenoptera: Apidae: Centridini) Journal of Economic Entomology, Lanham, v.102, n.1, p.265-273, 2009.

PAIVA, J. R. et al. Parâmetros genéticos em progênies de polinização livre de acerola. Pesquisa Agropecuária Brasileira, Brasília, v.34, n.4, p.629634. 1999.
PARAÍBA. Atlas geográfico do Estado da Paraíba. João Pessoa: Grafset, 1985. 100p.

RAW, A. Centris dirrhoda (Anthophoridae), the bee visiting West Indian cherry flowers (Malpighia punicifolia). Revista de Biologia Tropical, San Jose, v. 27, p.203-205. 1979.

RICKETTS, T. H. et al. Landscape effects on crop pollination services: are there general patterns? Ecology Letters, Hoboken, v.11, p.499-515, 2008.

ROUBIK, D. W. The value of bees to the coffee harvest. Nature, London, v.417, n.13, p.708, 2002.

VILHENA, A. M. G. F.; AUGUSTO, S. C. Polinizadores da aceroleira Malpighia emarginata DC (Malpighiaceae) em área de Cerrado no Triângulo Mineiro. Bioscience Journal, Uberlândia, v.23, Suppl. 1, p.14-23, 2007.

SCHLINDWEIN, C. et al. Diagnóstico e manejo dos polinizadores de mangabeira e aceroleira. In: ENCONTRO SOBRE ABELHAS, 7., 2006, Ribeirão Preto. Anais... Ribeirão Preto: Universidade de São Paulo, FFCLRP, 2006. p.443-454.

ZANELLA, F. C. V. Dinâmica temporal e espacial de abelhas solitárias no semiárido do Nordeste do Brasil. In: ENCONTRO SOBRE ABELHAS, 8., 2008, Ribeirão Preto. Anais... Ribeirão Preto: Universidade de São Paulo, FFCLRP, 2008. p.284-291.

ZANELLA, F. C. V.; MARTINS, C. F. Abelhas da Caatinga: biogeografia, ecologia e conservação. In: LEAL, I. R.; TABARELLI, M.; SILVA J. M. C. (Org.). Ecologia e conservação da Caatinga. Recife: Ed. Universitária da UFPE, 2003. p.75-134. 